\title{
Online Appendix: Intergenerational Human Capital Spillovers: Indonesia's school construction and its effects on the next generation
}

Bhashkar Mazumder (Federal Reserve Bank of Chicago and University of Bergen), Maria Rosales-Rueda (Rutgers University), Margaret Triyana (University of Notre Dame)

\begin{abstract}
Appendix A
Appendix A1. Coverage of the IFLS and INPRES program

We compare the intensity of the INPRES school construction project in the IFLS and IFLS-E against the national record. The IFLS provinces include 13 out of Indonesia's 26 provinces in 1993. They include: North Sumatra, West Sumatra, South Sumatra, Lampung, Jakarta, West Java, Central Java, Yogyakarta, East Java, Bali, West Nusa Tenggara, South Kalimantan, and South Sulawesi. The IFLS-E provinces include the following 7 provinces in 2012: East Nusa Tenggara, East Kalimantan, Southeast Sulawesi, Maluku, North Maluku, West Papua, and Papua. The IFLS and IFLS-E include almost 300 of Indonesia's 519 districts. ${ }^{1}$
\end{abstract}

Figure A.1 shows the intensity of the INPRES program in the IFLS and IFLS-E districts. Figure A.2 shows the intensity of the INRES program at the national level. A comparison of Figures A.1 and A. 2 shows that the IFLS and IFLS-E include both high and low intensity program districts.

\footnotetext{
${ }^{1}$ Indonesia experienced district proliferation between 1993 and 2014. To take this into account, we use the district crosswalk to consistently code district of birth based on the 1993 list of districts.
} 
Figure A.1. INPRES exposure in the IFLS and IFLS-E districts

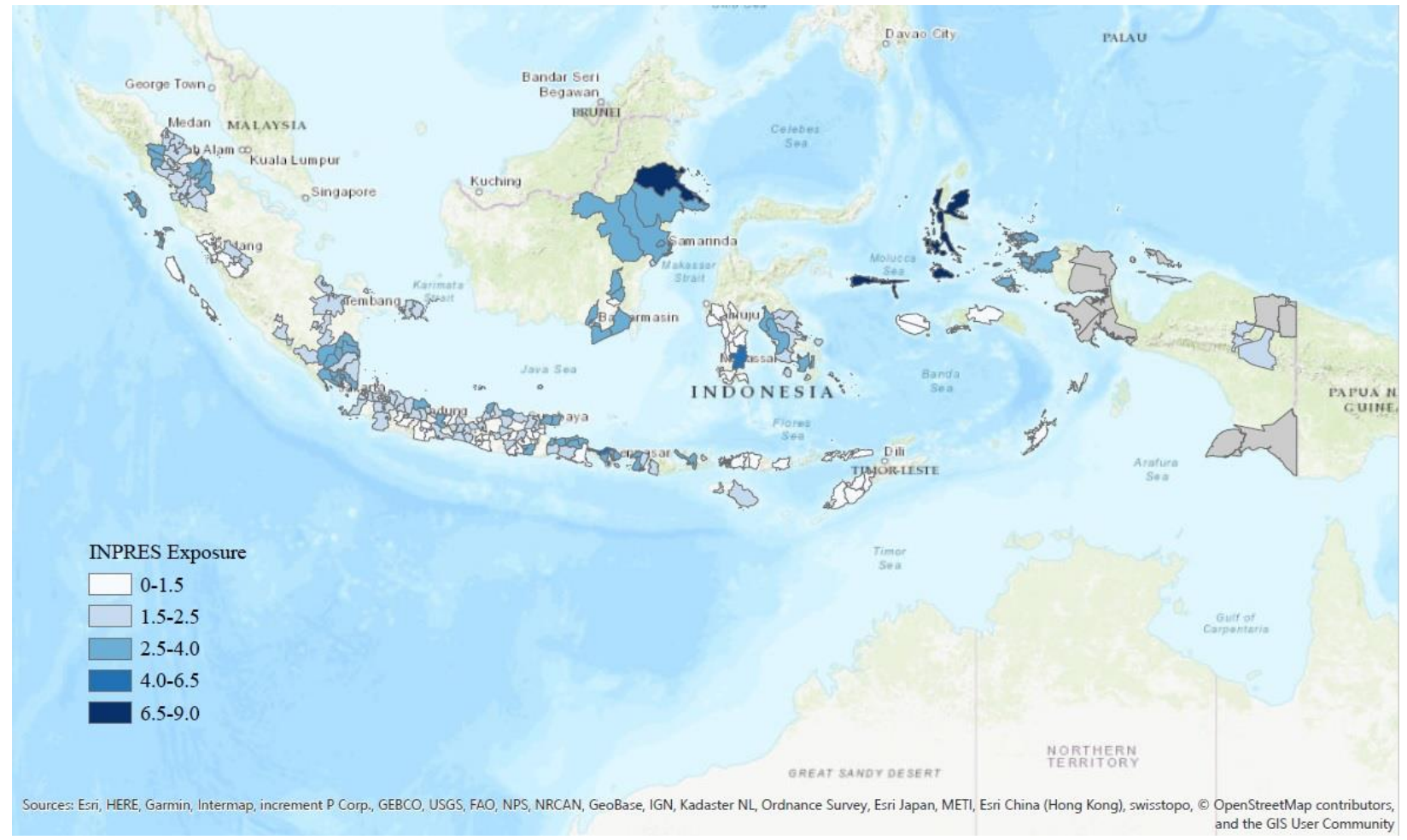

Source: Authors' calculations based on the IFLS, IFLS-E, and Duflo (2001) 
Figure A.2. Intensity of the INPRES program

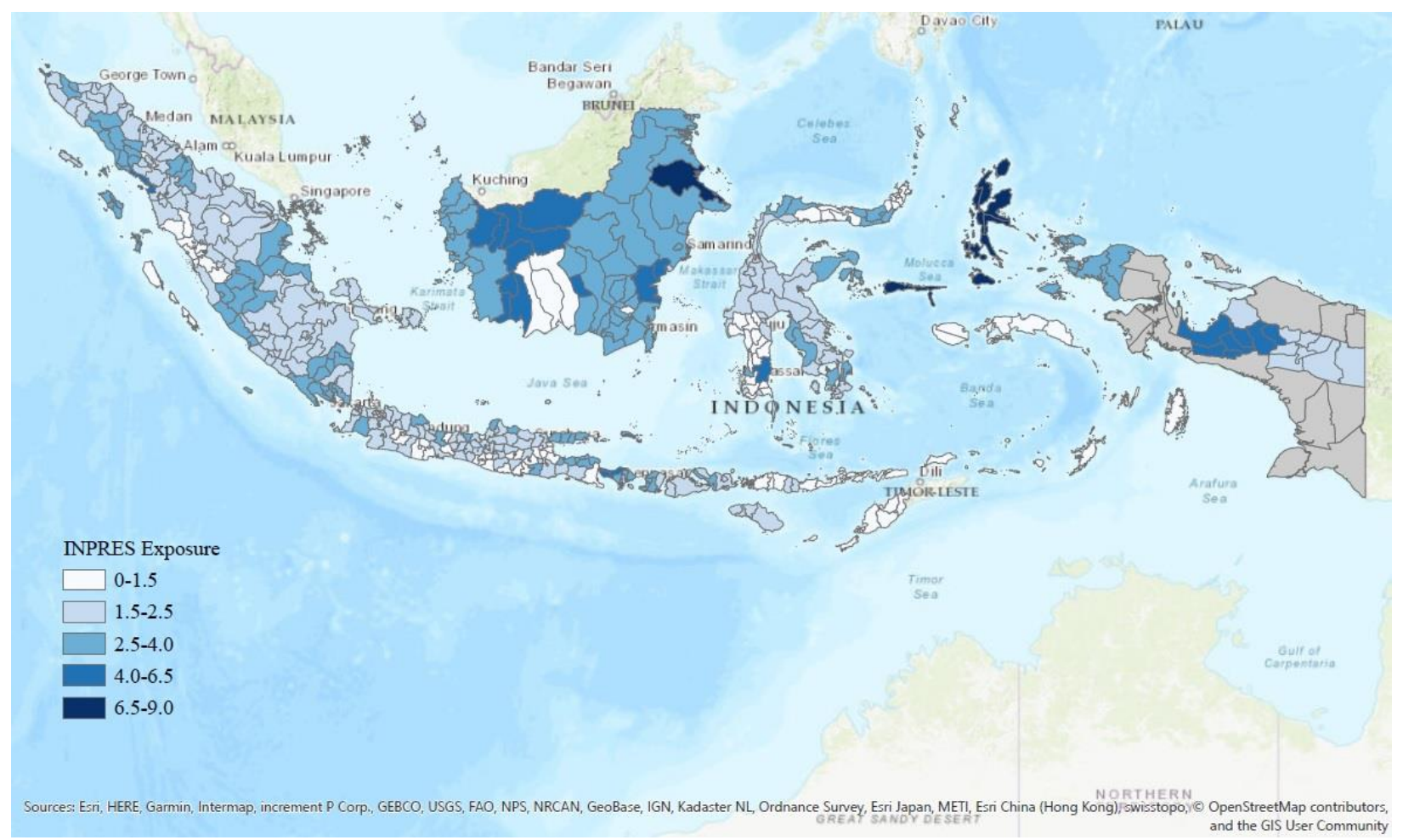

Source: Authors' calculations based on Duflo (2001) 


\section{Appendix A2. Validation of empirical strategy}

We use the nationally representative 1985 Intercensal survey (SUPAS 1985) to validate our empirical strategy. We use cohorts born between 1935 and 1958, who were older than primary school age when the INPRES program was implemented, to show trends in primary school completion rates in high and low program intensity districts. High program districts are defined as districts "where the residual of a regression of the number of schools on the number of children is positive" (Duflo, 2001). We show these similar trends in primary completion rates for males and females in Figure A.3.

We also estimate difference-in-differences model that interacts the number of INPRES schools and year of birth for these older cohorts. We estimate the following equation:

$$
y_{i d t}=\beta \text { yob }_{t} * \text { Inpres }_{d}+\sum_{t}\left(P_{d} * \tau_{t}\right) \delta_{t}+\alpha_{d}+\tau_{t}+\varepsilon_{\text {idt }}
$$

where yob is the year of birth dummy (1935 is the omitted category). Inpres ${ }_{d}$ captures the intensity of the program: the number of INPRES schools (per 1000 school-aged children) built in birth district $d . \alpha_{d}$ and $\tau_{t}$ are district and year-of-birth fixed effects. $P_{d} * \tau_{t}$ captures birth-year fixed effects interacted with the following district-level covariates: the number of school-aged children in the district in 1971 (before the start of the program), the enrollment rate of the district in 1971 and the exposure of the district to a contemporaneous water and sanitation program. Standard errors are clustered at the district of birth level. We estimate the model for males and females separately and plot these coefficients in Figure A.4. We also estimate placebo regressions on the first and second generation that we show below (Table A.3 and Table A.4, col. 3 respectively). 
Figure A.3. Pre-trends in primary school completion - raw data - SUPAS 1985
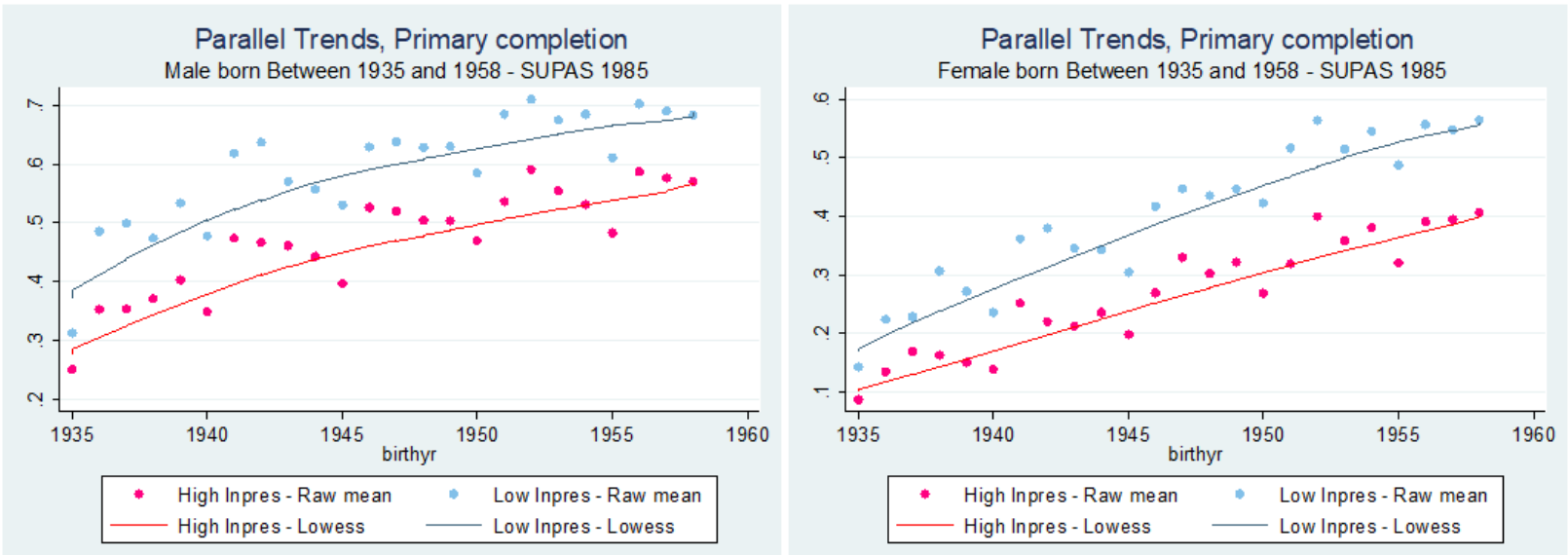

Notes: Primary completion rates for cohorts born between 1935 and 1958 from the 1985 Intercensal survey (SUPAS 1985).

Figure A.4. Pre-trends in primary school completion - regression coefficients - SUPAS 1985
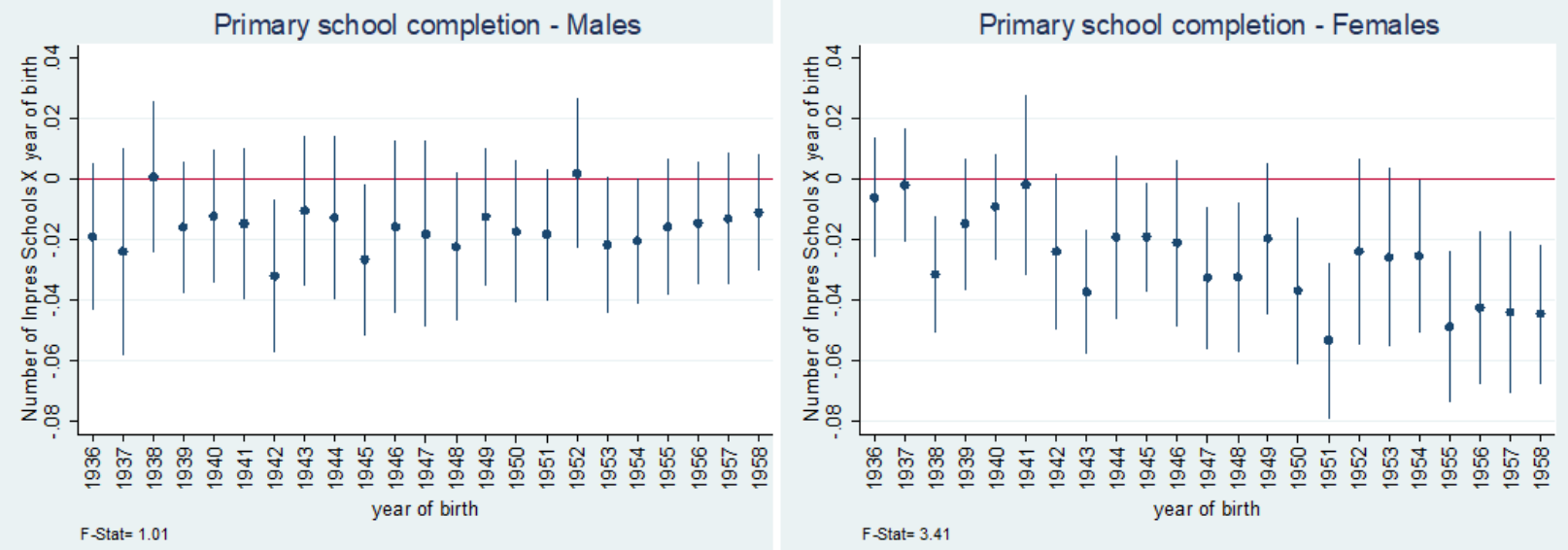

Notes: Coefficients from difference-in-differences model that interacts the number of INPRES schools and year of birth for cohorts born between 1935 and 1958. 


\section{Appendix A3. Additional Results}

Table A.1. First generation outcome: years of schooling

(2)

(3)

(4)

(5)

(6)

$\underline{\text { Full }} \underline{\text { Restricted }}$

All Male Female All Male Female

\section{Born between 1963-}

$\begin{array}{lcccccc}1972 & 0.163 & 0.077 & 0.237 & 0.247 * & 0.193 & 0.238 \\ \text { X Inpres } & (0.126) & (0.136) & (0.154) & (0.129) & (0.152) & (0.178) \\ & & & & & & \\ \text { Observations } & 13,792 & 6,942 & 6,850 & 7,613 & 3,841 & 3,772 \\ \text { R-squared } & 0.316 & 0.276 & 0.365 & 0.317 & 0.299 & 0.369 \\ \text { Y-Mean } & 7.47 & 8.24 & 6.69 & 7.91 & 8.59 & 7.22\end{array}$

Notes: Full sample corresponds to individuals born between 1950 and 1972. The restricted sample corresponds to individuals born between 1957 and 1962, or 1968 to 1972. Covariates include the following FE: year of birthx1971 enrollment, year of birthx1971 number of children, year of birthxwater sanitation program, district of birth, year and month of birth dummies, ethnicity (Javanese dummy). Robust standard errors in parentheses clustered at the district of birth. *** $\mathrm{p}<0.01, * * \mathrm{p}<0.05, * \mathrm{p}<0.1$ 
Table A.2. First Generation effect on primary completion: SUPAS 2005

(1)

All

(2)

Male

Panel A: First generation full sample (1950-1972)

Born between 1963-1972

$\mathrm{X}$ Inpres

$0.021 * * *$

(0.005)

$0.020 * * *$

$0.019 * * *$

Observations

R-squared

247,317

0.122

0.79

(0.005)

(0.005)

Y-Mean

Yanel B:

126,727

0.091

120,590

0.13

0.83

0.74 1972)

$\begin{array}{lccc}\text { Born between 1963-1972 } & 0.024 * * * & 0.020 * * * & 0.031 * * * \\ \text { X Inpres } & (0.006) & (0.006) & (0.007) \\ & & & \\ \text { Observations } & 132,998 & 67,833 & 65,165 \\ \text { R-squared } & 0.11 & 0.084 & 0.128 \\ \text { Y-Mean } & 0.79 & 0.85 & 0.78\end{array}$

Notes: Panel A sample corresponds to individuals born between 1950 and 1972. Panel B sample corresponds to individuals born between 1957 and 1962, or 1968 to 1972. Covariates include the following FE: year of birthx1971 enrollment, year of birthx1971 number of children, year of birthxwater sanitation program, district of birth, year and month of birth dummies, ethnicity (Javanese dummy). Robust standard errors in parentheses clustered at the district of birth. $* * * \mathrm{p}<0.01, * * \mathrm{p}<0.05, * \mathrm{p}<0.1$ 
Table A.3. Placebo first generation: primary completion

(1) (2) (3)

All Male Female

$\begin{array}{llll}\text { Placebo exposed } & -0.012 & -0.011 & -0.009 \\ \text { X INPRES } & (0.013) & (0.022) & (0.021)\end{array}$

X INPRES $\quad(0.013) \quad(0.022) \quad(0.021)$

\begin{tabular}{llll} 
Observations & 6,213 & 3,080 & 3,133 \\
R-squared & 0.246 & 0.251 & 0.288 \\
\hline
\end{tabular}

Notes: Sample corresponds to individuals born between 1950 and 1962. Placebo exposed takes the value one if individual $i$ was born between 1957 and 1962. Covariates include the following FE: year of birthx1971 enrollment, year of birthx1971 number of children, year of birthxwater sanitation program, district of birth, year and month of birth dummies, ethnicity (Javanese dummy). Robust standard errors in parentheses clustered at the district of birth. $* * * \mathrm{p}<0.01, * * \mathrm{p}<0.05, * \mathrm{p}<0.1$ 
Table A.4. Second generation standardized test scores: alternative specifications

(1)

(2)

\section{Children born to either INPRES \\ mother or father}

\begin{tabular}{ccc} 
Full sample & $\begin{array}{c}\text { Restricted } \\
\text { sample }\end{array}$ & $\begin{array}{c}\text { Placebo } \\
\text { regression }\end{array}$ \\
\hline
\end{tabular}

$\begin{array}{lccc}\text { Mother exposed } & 0.094^{* *} & 0.117^{*} & -0.059 \\ \text { X INPRES } & (0.046) & (0.063) & (0.080) \\ \text { Father exposed } & -0.029 & 0.005 & -0.057 \\ \text { X INPRES } & (0.038) & (0.044) & (0.063) \\ \text { Observations } & 9,258 & 6,301 & 2.959 \\ \text { Dep. var. mean } & 0.034 & 0.039 & 0.074 \\ \text { R-squared } & 0.17 & 0.17 & 0.27\end{array}$

Notes: Columns 1 and 2 display an alternative estimation of the effect of maternal INPRES exposure, where we include the father's cohort of birth, father's province of birth and the interaction of father's district of birth and cohort indicators. Column 1 sample corresponds to children born to first generation mothers or fathers in the full sample (born between 1950 and 1972) and mother/father exposed captures whether the mother/father was born between 1963 and 1972. Column 2 sample corresponds to children born to first generation mothers or fathers in the restricted sample (born between 1957-1962 or between 1968 and 1972) and mother/father exposed captures whether the mother/father was born between 1968 and 1972 (fully treated). Column 3 shows a placebo regression of maternal and paternal exposure on the sample of children born to parents not exposed to the INPRES program (parents born between 1950 and 1962). Under the placebo, mother/father exposed takes the value one if mother/father was born between 1957 and 1962. Robust standard errors in parentheses clustered at the parent's district of birth. $* * * \mathrm{p}<0.01, * * \mathrm{p}<0.05, * \mathrm{p}<0.1$ 
Table A.5. Second generation test scores: Controlling for the other parent's INPRES exposure

(1)

\begin{tabular}{|c|c|c|c|c|}
\hline \multirow[b]{3}{*}{ Focus Parent } & \multirow{2}{*}{\multicolumn{2}{|c|}{$\begin{array}{l}\text { (1) } \\
\text { Full sample }\end{array}$}} & \multirow{2}{*}{\multicolumn{2}{|c|}{$\begin{array}{l}(3) \\
\text { Restricted sample }\end{array}$}} \\
\hline & & & & \\
\hline & Mother & Father & Mother & Father \\
\hline Mother exposed & $0.080 * *$ & 0.032 & $0.118^{*}$ & 0.082 \\
\hline X INPRES & $(0.040)$ & $(0.033)$ & $(0.067)$ & $(0.057)$ \\
\hline Father exposed & -0.020 & -0.008 & 0.006 & -0.002 \\
\hline$X$ INPRES & $(0.026)$ & $(0.035)$ & $(0.041)$ & $(0.048)$ \\
\hline Observations & 8,563 & 8,169 & 4,499 & 3,941 \\
\hline Dep. Var. mean & 0.028 & 0.041 & 0.049 & 0.042 \\
\hline $\mathrm{R}$-squared & 0.17 & 0.14 & 0.16 & 0.15 \\
\hline
\end{tabular}

Notes: Column 1 (Column 2) sample corresponds to children born to mothers (fathers) born between 1950 and 1972, adding father's (mother's) exposure and controlling for father (mother) cohort of birth and the number of INPRES schools in the father's (mother's) district of birth. Mother (father) exposed indicates whether the mother(father) was born between 1963 and 1972. Column 3 (Column 4) sample corresponds to children born to mothers (fathers) in the restricted sample (mothers/father born between 1957 and 1962 or between 1968 and 1972) adding father's (mother's) exposure and controlling for father (mother) cohort of birth and the number of INPRES schools in the father's (mother's) district of birth. Mother (father) exposed takes the value one if the mother(father) was born between 1968 and 1972 (fully exposed). Covariates include the following FE: focus parent year of birth and district of birth fixed effects, focus parent year of birthx1971 enrollment, focus parent year of birthx1971 number of children, focus parent year of birthxwater sanitation program, child's gender, birth order, year and month of birth dummies, urban, ethnicity (Javanese indicator). The number of observations is lower than those in the main table because of the other parent missing information in cohort or district of birth. Robust standard errors in parentheses clustered at the focus parent's district of birth. *** $\mathrm{p}<0.01, * * \mathrm{p}<0.05, * \mathrm{p}<0.1$ 


\section{Appendix B}

\section{Appendix B1. Data construction}

We use longitudinal data from 5 waves of the Indonesian Family Life Survey (IFLS) and the Indonesian Family Life Survey-East (IFLS-E), which includes one wave in 2012. The first wave of the survey (IFLS1) was conducted in 1993, the second wave (IFLS2) in 1997, the third wave (IFLS3) in 2000, the fourth wave (IFLS4) in 2007, and the fifth wave (IFLS5) in 2014. The IFLS-E is modeled after the IFLS, and covers 7 provinces in the eastern part of Indonesia that were excluded by the IFLS.

Date of birth:

To obtain the sample of first individuals, we begin by identifying individuals who were born between 1950 and 1972 in the IFLS and IFLS-E. In each wave, the IFLS household roster includes information on date of birth, so we first harmonize year and month of birth for IFLS respondents since a respondent in the IFLS may report his/her date of birth 5 times over the years.

If the reported year of birth is inconsistent across waves, we assume a respondent's year of birth is the mode across waves. In cases where the mode does not exist, we use the first reported year of birth.

To take into account the seasonality of birth, we also include month of birth in our analysis. We follow the same method to harmonize month of birth for individuals across waves. This implies that in some cases, the year and month of birth may be based on different waves of the survey.

\section{District of birth:}

The IFLS asks respondents over the age of 15 their place of birth in the wave in which they first join the survey. Indonesia experienced district proliferation over time, so we match each district to the 1993 district code in IFLS1.

INPRES school construction in the district, water and sanitation program, enrolment in 1971, number of school-aged children in 1971: 
We obtain these variables from Duflo (2001).

Linking the first and second generation:

To identify the second generation, who are the children of the first generation individuals, we use the household relationship in the household roster and women's birth history, matched to the household roster. In each wave, the survey includes an individual's relationship to the head of the household, and an identifier for an individual's mother and father if the mother and father are in the same household. The IFLS also includes a woman's birth history, which allows us to match mothers to their children, and subsequently to children's outcomes.

Ethnicity:

The IFLS started collecting information on ethnicity in 2000 (IFLS3). We create an indicator for Javanese, the majority group in Indonesia and the IFLS. We code an individual as Javanese if he/she ever self-identified as Javanese.

\section{$\underline{\text { Appendix B2. }}$}

\section{Additional first generation results: A comparison of the IFLS, IFLS-E and the SUPAS}

In the following tables, we show estimations of the first-generation's primary school completion rates using only control covariates used by Duflo (2001) and the inclusion of our additional covariates (month of birth and ethnicity). We start with a comparison of the results using the IFLS and IFLS-East data, followed by the estimations using the IFLS data only (Table B.1). We then show the estimations using the Intercensal Surveys in 1995 and 2005 (SUPAS 1995 and 2005) in Tables B.2 and B.3 respectively. We estimate the models for the full (those born between 1950 and 1972) and restricted samples (individuals born between 1957 and 1962, or 1968 to 1972 ).

Table B.1 presents alternative covariates in estimating the effect of INPRES exposure on the first generation. In odd columns, we follow Duflo (2001) and use the following covariates: district and year-of-birth fixed effects, and birth-year fixed effects interacted with the following districtlevel covariates: the number of school-aged children in the district in 1971 (before the start of the 
program), the enrollment rate of the district in 1971 and the exposure of the district to a contemporaneous water and sanitation program. Even columns add month of birth fixed effects and ethnicity, which is an indicator for Javanese, the majority in Indonesia. A comparison of the odd and even columns show that the estimated effects are not driven by the inclusion of the ethnicity dummy and month of birth fixed effects.

A comparison of panel A and panel B of Table B.1 shows that the estimated program effect on the first generation's primary completion using the IFLS alone is small and not statistically significant, but the estimated effect is substantial and significant with the inclusion of IFLS-E. We believe this is because the IFLS excludes the eastern part of Indonesia, which is historically poorer and was more likely to receive the INPRES school construction project with a higher intensity. Thus, the inclusion of the IFLS-E not only increases sample size, but increases the program coverage in our sample. 
Table B.1. First generation primary completion: Alternative covariates

\begin{tabular}{|c|c|c|c|c|c|c|c|c|c|c|c|c|}
\hline & (1) & (2) & (3) & (4) & (5) & (6) & (7) & (8) & (9) & $(10)$ & (11) & (12) \\
\hline & \multicolumn{6}{|c|}{ Full sample } & \multicolumn{6}{|c|}{$\underline{\text { Restricted sample }}$} \\
\hline & \multicolumn{2}{|c|}{ All } & \multicolumn{2}{|c|}{ Male } & \multicolumn{2}{|c|}{ Female } & \multicolumn{2}{|c|}{ All } & \multicolumn{2}{|c|}{ Male } & \multicolumn{2}{|c|}{ Female } \\
\hline & Cov. 1 & Cov. 2 & Cov. 1 & Cov. 2 & Cov. 1 & Cov. 2 & Cov. 1 & Cov. 2 & Cov. 1 & Cov. 2 & Cov. 1 & Cov. 2 \\
\hline \multicolumn{13}{|c|}{ Panel A. IFLS and IFLS-E } \\
\hline $\begin{array}{l}\text { Young } \\
X\end{array}$ & $0.028 * *$ & $0.028 * *$ & $0.025^{*}$ & $0.025^{*}$ & $0.030 *$ & $0.030 *$ & $0.044 * * *$ & $0.044 * * *$ & $0.038 * *$ & $0.032 *$ & $0.048 * * *$ & $0.052 * * *$ \\
\hline INPRES & $(0.013)$ & $(0.014)$ & $(0.015)$ & $(0.014)$ & $(0.016)$ & $(0.017)$ & $(0.014)$ & $(0.014)$ & $(0.018)$ & $(0.017)$ & $(0.017)$ & $(0.018)$ \\
\hline $\begin{array}{l}\text { Obs. } \\
\text { R- }\end{array}$ & 14,468 & 13,856 & 7,240 & 6,991 & 7,228 & 6,865 & 7,930 & 7,650 & 3,975 & 3,869 & 3,955 & 3,781 \\
\hline squared & 0.236 & 0.252 & 0.211 & 0.232 & 0.273 & 0.29 & 0.24 & 0.256 & 0.247 & 0.271 & 0.274 & 0.29 \\
\hline \multicolumn{13}{|c|}{ Panel B. IFLS only } \\
\hline $\begin{array}{l}\text { Young } \\
X\end{array}$ & 0.001 & 0.004 & -0.004 & 0.001 & 0.004 & 0.006 & 0.012 & 0.012 & 0.007 & 0.003 & 0.017 & 0.019 \\
\hline INPRES & $(0.014)$ & $(0.014)$ & $(0.017)$ & $(0.017)$ & $(0.017)$ & $(0.018)$ & $(0.016)$ & $(0.016)$ & $(0.021)$ & $(0.021)$ & $(0.020)$ & $(0.019)$ \\
\hline $\begin{array}{l}\text { Obs. } \\
\text { R- }\end{array}$ & 12,651 & 12,321 & 6,326 & 6,185 & 6,325 & 6,136 & 6,923 & 6,779 & 3,484 & 3,432 & 3,439 & 3,347 \\
\hline squared & 0.254 & 0.274 & 0.227 & 0.249 & 0.291 & 0.312 & 0.259 & 0.278 & 0.261 & 0.282 & 0.292 & 0.312 \\
\hline
\end{tabular}

to 1972. Young takes the value 1 if an individual is born between 1963 and 1972. Cov. 1 includes covariates included in Duflo (2001). Those covariates include the following FE: year of birthx1971 enrollment, year of birthx1971 number of children, year of birthxwater sanitation program, year of birth, district of birth. Cov. 2 adds month of birth dummies and ethnicity (Javanese dummy). Robust standard errors in parentheses clustered at the district of birth. *** p<0.01, ** $\mathrm{p}<0.05, * \mathrm{p}<0.1$. 
We further explore the representativeness of combination of the IFLS and IFLS-E using the Intercensal Surveys in 1995 and 2005 (SUPAS) in Tables B.2 and B.3 below. We follow Duflo (2001) and use the SUPAS 1995 in Table B.2. We estimate the models for all of Indonesia (Panel A), the provinces covered by the combination of the IFLS and IFLS-E (Panel B), and the provinces covered by the IFLS (Panel C). Table B.2, using SUPAS 1995, shows that the program effect on primary completion is concentrated among males, which is consistent with earlier findings (Duflo, 2001). Since the coverage of the SUPAS 1995 and SUPAS 2005 is different, we also use the SUPAS 2005 to compare the IFLS and IFLS-E coverage to another nationally representative sample.

Table B.3, using SUPAS 2005, shows that the program effect on primary completion is significant for both males and females. When we compare the estimated effects for all of Indonesia (Panel A) and the combination of IFLS and IFLS-E provinces (Panel B), the estimated effects are very similar. Additionally, the SUPAS 2005 estimate in Panel B is similar to our main finding using the IFLS and IFLS-E data (Table 1). The estimated effects are slightly smaller and noisier when we restrict the SUPAS 2005 sample to the main IFLS provinces (Panel C). 
Table B.2. First generation primary completion: SUPAS 1995

\begin{tabular}{|c|c|c|c|c|c|c|c|c|c|c|c|c|}
\hline & (1) & (2) & (3) & (4) & (5) & (6) & (7) & (8) & (9) & $(10)$ & (11) & (12) \\
\hline & \multicolumn{6}{|c|}{ Full Sample } & \multicolumn{6}{|c|}{ Restricted Sample } \\
\hline & \multicolumn{2}{|c|}{ All } & \multicolumn{2}{|c|}{ Male } & \multicolumn{2}{|c|}{ Female } & & & & & & \\
\hline & Cov. 1 & Cov. 2 & Cov. 1 & Cov. 2 & Cov. 1 & Cov. 2 & Cov. 1 & Cov. 2 & Cov. 1 & Cov. 2 & Cov. 1 & Cov. 2 \\
\hline \multicolumn{13}{|c|}{ Panel A: All Indonesian Provinces } \\
\hline $\begin{array}{l}\text { Young } \\
\text { X INPRES }\end{array}$ & $\begin{array}{c}0.001 \\
(0.005)\end{array}$ & $\begin{array}{c}0.003 \\
(0.005)\end{array}$ & $\begin{array}{c}0.011 * \\
(0.006)\end{array}$ & $\begin{array}{c}0.009 \\
(0.006)\end{array}$ & $\begin{array}{c}-0.008 \\
(0.007)\end{array}$ & $\begin{array}{l}-0.001 \\
(0.007)\end{array}$ & $\begin{array}{c}0.003 \\
(0.007)\end{array}$ & $\begin{array}{c}0.006 \\
(0.007)\end{array}$ & $\begin{array}{c}0.016 * * \\
(0.007)\end{array}$ & $\begin{array}{l}0.013 * \\
(0.007)\end{array}$ & $\begin{array}{l}-0.007 \\
(0.008)\end{array}$ & $\begin{array}{c}0.002 \\
(0.008)\end{array}$ \\
\hline Obs. & 213,167 & 169,162 & 104,349 & 84,136 & 108,818 & 85,026 & 162,684 & 127,634 & 80,251 & 63,976 & 82,433 & 63,658 \\
\hline R-squared & 0.157 & 0.121 & 0.123 & 0.092 & 0.172 & 0.138 & 0.167 & 0.131 & 0.13 & 0.101 & 0.187 & 0.151 \\
\hline
\end{tabular}

Panel B: IFLS and IFLS East Provinces

\begin{tabular}{|c|c|c|c|c|c|c|c|c|c|c|c|c|}
\hline $\begin{array}{l}\text { Young } \\
\text { X INPRES }\end{array}$ & $\begin{array}{c}0.001 \\
(0.006)\end{array}$ & $\begin{array}{c}0.003 \\
(0.005)\end{array}$ & $\begin{array}{c}0.013 * * \\
(0.006)\end{array}$ & $\begin{array}{c}0.011 \\
(0.007)\end{array}$ & $\begin{array}{l}-0.009 \\
(0.007)\end{array}$ & $\begin{array}{l}-0.002 \\
(0.007)\end{array}$ & $\begin{array}{c}0.003 \\
(0.007)\end{array}$ & $\begin{array}{c}0.007 \\
(0.007)\end{array}$ & $\begin{array}{c}0.019 * * \\
(0.008)\end{array}$ & $\begin{array}{c}0.016 * * \\
(0.007)\end{array}$ & $\begin{array}{l}-0.009 \\
(0.009)\end{array}$ & $\begin{array}{c}0.003 \\
(0.008)\end{array}$ \\
\hline Obs. & 187,518 & 149,445 & 91,443 & 74,073 & 96,075 & 75,372 & 143,297 & 112,942 & 70,401 & 56,395 & 72,896 & 56,547 \\
\hline R-squared & 0.16 & 0.122 & 0.126 & 0.094 & 0.176 & 0.14 & 0.171 & 0.132 & 0.134 & 0.103 & 0.191 & 0.153 \\
\hline
\end{tabular}

Notes: SUPAS 1995 from IPUMS-I. Full sample corresponds to individuals born between 1950 and 1972 . Restricted sample corresponds to individuals born between 1957 and 1962, or 1968 to 1972 . Young takes the value 1 if an individual is born between 1963 and 1972 . Cov. 1 includes covariates included in Duflo (2001). Those covariates include the following FE: year of birthx1971 enrollment, year of birthx1971 number of children, year of birthxwater sanitation program, year of birth, district of birth. Cov. 2 adds month of birth dummies and ethnicity (Javanese dummy). Robust standard errors in parentheses clustered at the district of birth. $* * * \mathrm{p}<0.01, * * \mathrm{p}<0.05, * \mathrm{p}<0.1$. 
Table B.2. First generation primary completion: SUPAS 1995 (continued)

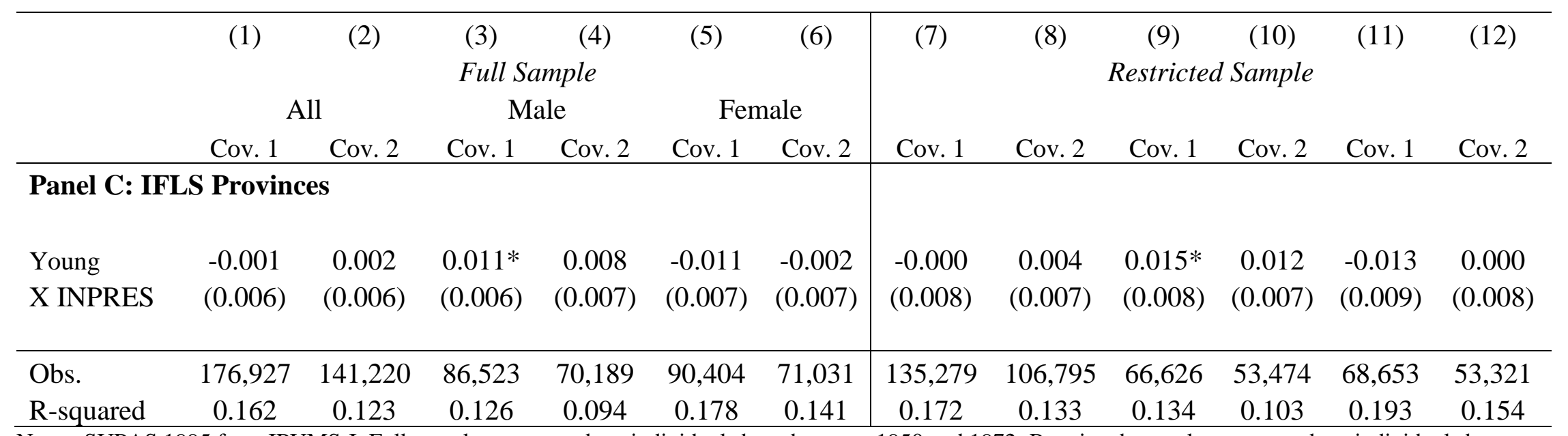

Notes: SUPAS 1995 from IPUMS-I. Full sample corresponds to individuals born between 1950 and 1972. Restricted sample corresponds to individuals born

between 1957 and 1962, or 1968 to 1972. Young takes the value 1 if an individual is born between 1963 and 1972. Cov. 1 includes covariates included in Duflo (2001). Those covariates include the following FE: year of birthx1971 enrollment, year of birthx1971 number of children, year of birthxwater sanitation program, year of birth, district of birth. Cov. 2 adds month of birth dummies and ethnicity (Javanese dummy). Robust standard errors in parentheses clustered at the district of birth. $* * * \mathrm{p}<0.01, * * \mathrm{p}<0.05, * \mathrm{p}<0.1$. 
Table B.3. First generation primary completion: SUPAS 2005

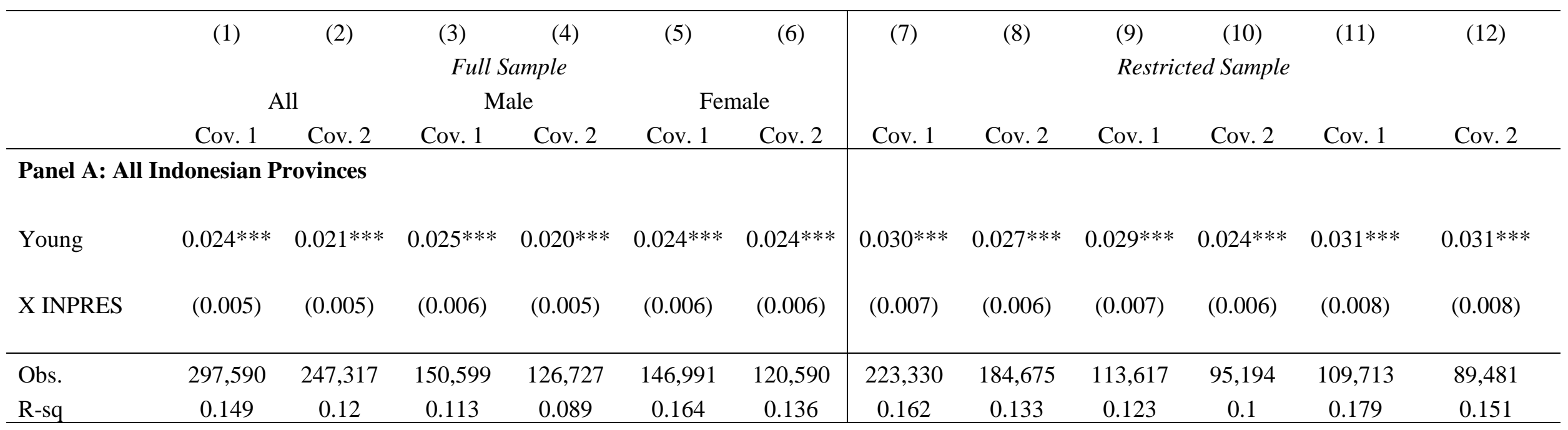

\section{Panel B: IFLS and IFLS East Provinces}

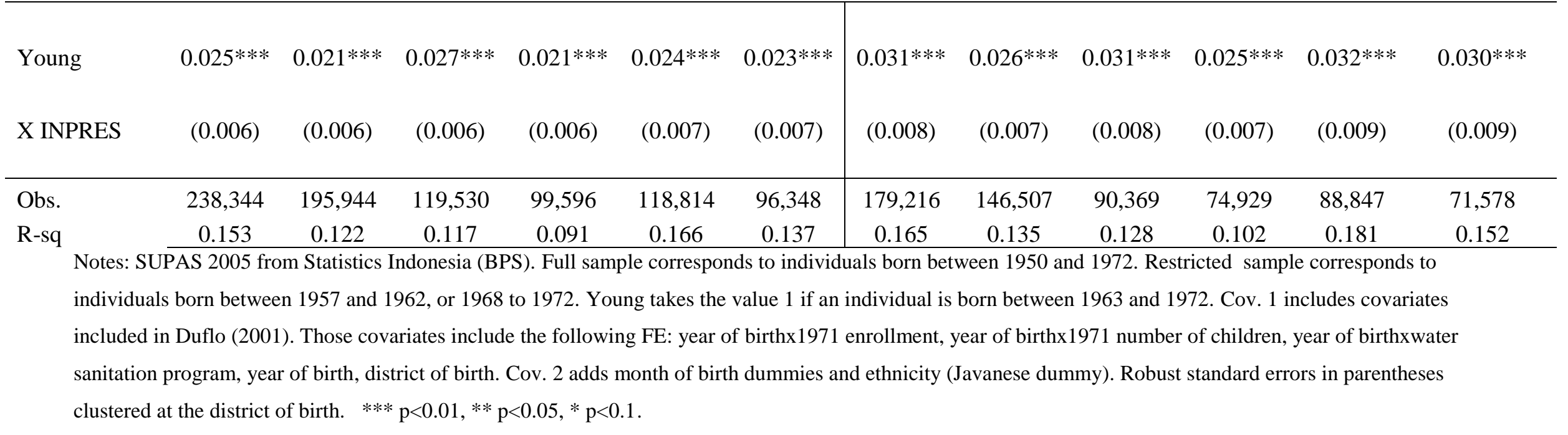


Table B.3. First generation primary completion: SUPAS 2005 (continued)

\begin{tabular}{|c|c|c|c|c|c|c|c|c|c|c|c|c|}
\hline & (1) & (2) & (3) & (4) & (5) & (6) & (7) & (8) & (9) & (10) & (11) & (12) \\
\hline & \multicolumn{6}{|c|}{ Full Sample } & \multicolumn{6}{|c|}{ Restricted Sample } \\
\hline & \multicolumn{2}{|c|}{ All } & \multicolumn{2}{|c|}{ Male } & \multicolumn{2}{|c|}{ Female } & & & & & & \\
\hline & Cov. 1 & Cov. 2 & Cov. 1 & Cov. 2 & Cov. 1 & Cov. 2 & Cov. 1 & Cov. 2 & Cov. 1 & Cov. 2 & Cov. 1 & Cov. 2 \\
\hline \multicolumn{13}{|c|}{ Panel C: IFLS Provinces } \\
\hline Young & $0.013 * *$ & 0.009 & $0.015 * *$ & 0.009 & 0.010 & 0.011 & $0.014 *$ & 0.011 & $0.016 * *$ & 0.010 & 0.013 & 0.014 \\
\hline X INPRES & $(0.006)$ & $(0.006)$ & $(0.007)$ & $(0.006)$ & $(0.007)$ & $(0.008)$ & $(0.007)$ & $(0.007)$ & $(0.008)$ & $(0.007)$ & $(0.009)$ & $(0.009)$ \\
\hline Obs. & 197,551 & 162,786 & 98,513 & 82,340 & 99,038 & 80,446 & 149,017 & 122,003 & 74,720 & 62,079 & 74,297 & 59,924 \\
\hline $\mathrm{R}-\mathrm{sq}$ & 0.151 & 0.124 & 0.114 & 0.093 & 0.165 & 0.139 & 0.165 & 0.138 & 0.126 & 0.105 & 0.181 & 0.155 \\
\hline
\end{tabular}

